\title{
Iodine intake before and after mandatory iodization in Denmark: results from the Danish Investigation of Iodine Intake and Thyroid Diseases (DanThyr) study
}

\author{
Lone B. Rasmussen $^{1 *}$, Allan Carlé2, Torben Jørgensen ${ }^{3}$, Nils Knudsen ${ }^{3,4}$, Peter Laurberg ${ }^{2}$,
} Inge B. Pedersen ${ }^{2}$, Hans Perrild ${ }^{4}$, Pernille Vejbjerg ${ }^{3,4}$ and Lars Ovesen ${ }^{5}$

${ }^{1}$ Department of Nutrition, National Food Institute, Technical University of Denmark, Mфrkhøj Bygade 19, DK-L 2860 Søborg, Denmark

${ }^{2}$ Department of Endocrinology, Aalborg Hospital, Aarhus University, Hobrovej 18-22, DK-9100 Aalborg, Denmark

${ }^{3}$ Research Centre for Prevention and Health, Copenhagen County, Ndr. Ringvej 57, DK-2600 Glostrup, Denmark

${ }^{4}$ Department of Endocrinology and Gastroenterology, Bispebjerg University Hospital, Bisbebjerg Bakke 23, DK-2400 Copenhagen, Denmark

${ }^{5}$ Department of Gastroenterology, Slagelse Hospital, Falledvej 1, DK-4200 Slagelse, Denmark

(Received 25 June 2007 - Revised 4 October 2007 - Accepted 1 November 2007 - First published online 22 January 2008)

Iodine deficiency is still common in some European countries. In Denmark an iodine fortification programme was introduced in 1998 and a monitoring programme was established prior to iodization. This study reports the change in urinary iodine excretion caused by fortification and investigates determinants of iodine intake after fortification. Iodine excretion in casual urine samples was assessed in 4649 subjects in 1997-8 and in 3570 comparable subjects in 2004-5 in women 18-22, 25-30, 40-45 and 60-65 years of age and in men 60-65 years of age living in Aalborg (western part of Denmark) or Copenhagen (eastern part of Denmark). These areas had moderate and mild iodine deficiency, respectively, before iodine fortification. All subjects filled in a FFQ and a questionnaire regarding lifestyle factors. Iodine excretion, expressed as the estimated $24 \mathrm{~h}$ urinary iodine excretion and as urinary iodine concentration, increased significantly in all age and sex groups. However, the iodine intake was still below the recommended in the youngest age groups in both cities and in women 40-45 years of age living in Aalborg. Intake of milk and salt had strong significant direct associations with iodine excretion $(P<0 \cdot 001)$. It is concluded that although the median iodine intake in the whole study population is at the recommended level, some groups still have an intake below the recommended. It is important to have a moderate milk intake to obtain a sufficient iodine intake in Denmark.

Iodine intake: Iodine excretion: Determinants of iodine intake: Denmark

Iodine (I) is an essential micronutrient. Despite the fact that iodized salt was introduced for the first time more than 80 years ago, I deficiency still exists in some European countries $^{(1)}$. In most European countries I-fortified salt is on the market, but the introduction year of I fortification as well as the iodization level and market share of iodized salt differ between countries ${ }^{(2)}$.

Iodization of salt has been proved to increase I intake and decrease the incidence of I deficiency diseases effectively, and an increase in I excretion after introduction of I fortification has been found with various levels of fortification ${ }^{(3)}$, and even with a small increase in the level of an already established fortification $^{(4)}$.

In Denmark voluntary I fortification at a level of 8 parts per million in all salt was introduced in 1998 because of a low I intake. Before I fortification was introduced in Denmark, the median I excretion was $68 \mu \mathrm{g} / \mathrm{l}$ in the eastern part of Denmark and $53 \mu \mathrm{g} / 1$ in the western part of Denmark ${ }^{(5)}$. Median I excretions in participants not taking daily I supplements were 61 and $45 \mu \mathrm{g} / \mathrm{l}$, respectively. Correspondingly, the prevalence of goitre was high, up to $33 \%$ in elderly women ${ }^{(6)}$. The geographical difference with lowest I intake in Aalborg in the western part of the country and highest intake in Copenhagen in the eastern part of the country can mainly be explained by the difference in I content in drinking water; approximately $5 \mu \mathrm{g} / \mathrm{l}$ in Aalborg and $18 \mu \mathrm{g} / \mathrm{l}$ in Copenhagen ${ }^{(7,8)}$.

Fortification of salt was initiated because of the low I intake. A cautious increase in I intake by the fortification of salt was planned to avoid serious side-effects. Thus, an average increase of $50 \mu \mathrm{g} / \mathrm{d}$ for adults was aimed at and the fortification level was determined based on calculations on the intake of salt in Denmark. Furthermore, in planning the fortification programme it was important that iodine would be equally distributed in the population and reach (nearly)

Abbreviations: C1, cross-sectional study before iodine fortification; C2, cross-sectional study after iodine fortification; DanThyr, Danish Investigation of Iodine Intake and Thyroid Diseases.

* Corresponding author: Dr Lone B. Rasmussen, fax +45 723471 19, email lbra@food.dtu.dk 
everyone. Therefore, at first instance all salt was chosen as the carrier. However, after one and a half year with voluntary fortification of all salt only a small part of salt used by the food industry was iodized. From the year 2000 the voluntary fortification of all salt was therefore changed to a mandatory fortification of bread salt and household salt at a level of $13 \mathrm{ppm}$. This fortification fulfilled the criteria given above.

To reach the optimal level of I in salt and thus the optimal I intake in a population, exploring the median I intake in a population is not sufficient. It is also important to identify subgroups with insufficient intake. Possible subgroups with low I intake could be identified by geography, age, sex, dietary habits or factors like smoking habits, BMI and education.

To evaluate the effect of an I fortification programme, monitoring is necessary with regard to possible positive as well as negative effects. In Denmark a monitoring programme named the Danish Investigation of Iodine Intake and Thyroid Diseases (DanThyr), takes advantage of this ${ }^{(9)}$. The DanThyr programme consists of three main parts, all started in 1997: (1) two cross-sectional studies - the first was performed in 1997-8 before I fortification was introduced and data collection in the second study was performed in 2004-5; (2) identification of new cases of overt hyper- and hypothyroidism in an open population cohort of more than 550000 people living in the same areas; and (3) a central register for surgical, medical and radioiodine treatment of thyroid disease in Denmark.

The aim of the present study was to investigate the I intake and the distribution of I intake before and after I fortification was introduced. Furthermore, the aim was to examine the intake in various groups to identify possible risk groups with regard to age and geography. Lastly, dietary determinants of the I intake after fortification were assessed.

\section{Subjects and methods}

Two cross-sectional studies were carried out: the first $(\mathrm{C} 1)$ was performed before fortification of salt was introduced in Denmark and the second (C2) was performed 4-5 years after mandatory iodization of salt. The cross-sectional studies took place at two centres located in the cities of Aalborg (situated in western part of Denmark) and Copenhagen (situated in eastern part of Denmark). The two cities represent areas with moderate and mild I deficiency, respectively, before fortification. For both studies a random sample was drawn from the Civil Registration System of all inhabitants in the two cities comprising the following groups (in $\mathrm{C} 2$ the sample excluded subjects participating in $\mathrm{C} 1$ ): women aged $18-22,25-30$, $40-45$ and $60-65$ years, and men aged $60-65$ years. These groups were chosen to represent women before the childbearing age, in the childbearing age and after the childbearing age, both premenopausal and postmenopausal. Primarily women were investigated as the occurrence of thyroid abnormalities were supposed to be higher among women than among men. In the first study 9274 subjects were invited and 4649 $(50.1 \%)$ participated. In the second study 7658 were invited and $3570(46.6 \%)$ participated.

The first cross-sectional study took place from 10 March 1997 to 1 June 1998 . The second study took place from 28 April 2004 to 14 July 2005. All information gathered and procedures performed were standardized in both cities and both studies. Both studies were approved by the regional ethical committees. All participants provided written, informed consent.

All participants completed questionnaires which gave information about smoking habits, alcohol consumption and education. Participants were asked to bring with them all dietary supplements taken. In the first study brand names, dose and frequency of usage were recorded. In the second study daily intake of I from dietary supplements was recorded. Both cross-sectional studies have been described in detail ${ }^{(6,10)}$.

\section{$F F Q$}

A FFQ was given to all participants in both studies when they arrived at the centre. The FFQ was filled in while waiting for a thyroid ultrasound examination and interview. The FFQ was semi-quantitative and was similar in both studies except that ten questions regarding bread intake were added to the questionnaire in $\mathrm{C} 2$ because of the I fortification of bread salt. Thus, the FFQ included a list of fifty-three I-rich food items in $\mathrm{C} 1$ and sixty-three in $\mathrm{C} 2$. The FFQ has been evaluated and described in more detail ${ }^{(11)}$. I intake was calculated for 4346 (93.0\%) participants in C1 and 3522 (98.7\%) in C2.

\section{Body weight and height}

Weight was measured to the nearest $0 \cdot 1 \mathrm{~kg}$, with normal indoor clothes and without shoes, with SECA analogue person medical scales. Height was measured to the nearest $\mathrm{cm}$, without shoes, using a stadiometer.

\section{Urine collections}

All participants were asked to give a urine sample when they visited the centre. These casual urine samples were analysed for I, creatinine and sodium. I excretion was expressed in two ways: as a concentration and as an estimated $24 \mathrm{~h}$ urinary I excretion. To calculate the estimated $24 \mathrm{~h}$ urinary I excretion we multiplied the I:creatinine ratio with the expected daily creatinine excretion for the given individual. The expected $24 \mathrm{~h}$ creatinine excretion was based on the data of Kesteloot \& Joossens ${ }^{(12)}$, with combination of some groups due to negligible variation. The $24 \mathrm{~h}$ creatinine excretion applied was $1.47 \mathrm{~g}$ for men (all aged 60-65 years), $1.23 \mathrm{~g}$ for women up to the age of 49 years and 1.07 for women 60-65 years of age. A satisfactory agreement between estimated $24 \mathrm{~h}$ urinary I excretion and observed $24 \mathrm{~h}$ urinary I excretion has been found ${ }^{(13,14)}$. Estimated $24 \mathrm{~h}$ sodium excretion was calculated the same way as estimated $24 \mathrm{~h}$ urinary I excretion. Estimated salt intake was calculated as the estimated $24 \mathrm{~h}$ sodium excretion multiplied by 2.5 . I concentration in urine was available for 4616 subjects in $\mathrm{C} 1$ and 3554 in $\mathrm{C} 2$, and estimated $24 \mathrm{~h}$ urinary I excretion for 4594 and 3553 subjects in $\mathrm{C} 1$ and $\mathrm{C} 2$, respectively.

A subsample of the participants was asked to collect one $24 \mathrm{~h}$ urine sample. Most participants in the age groups 25-30 years and women 60-65 years participating during the last half of the studies were asked to collect one $24 \mathrm{~h}$ urine sample: 156 and 116 agreed, respectively. Morning urine on the first day was not collected. The morning urine on day 2 was the last sample collected. Urine was stored cold and received at the laboratory within $2 \mathrm{~d}$ after collection, 
volumes were estimated by weight (assuming a specific gravity of $1 \mathrm{~g} / \mathrm{ml}$ ) and $5 \mathrm{ml}$ samples were stored at $-20^{\circ} \mathrm{C}$ until analysis. Urine samples were validated for completeness with para-aminobenzoic acid ${ }^{(15)}$. In $\mathrm{C} 1$ twenty-eight of the 156 samples and in $\mathrm{C} 2$ thirteen of the 116 samples were rejected due to incomplete collection.

Assays. I in urine was measured by the $\mathrm{Ce}-\mathrm{As}$ method after alkaline ashing ${ }^{(16)}$ as described previously ${ }^{(17)}$. The recovery of ${ }^{127} \mathrm{I}$ (corresponding to $32 \mu \mathrm{g} / \mathrm{l}$ ) when added to fifteen urine samples with a median I content of 35 (range 15-80) $\mu \mathrm{g} / \mathrm{l}$ was 95.9 (SEM2.4) \%. Final values were not corrected for percentage recovery. Serial dilutions of fifteen urine samples containing $15-80 \mu \mathrm{g} \mathrm{I} / \mathrm{l}$ gave curves parallel to the standard curve. When a urine sample measured to contain $93.9 \mu \mathrm{g} / \mathrm{l}$ was measured in triplicate in eighteen assays, the intra- and inter-assay $\mathrm{CV}$ for single determinations were 2.1 and $2.7 \%$, respectively. The lowest standard above the zero blank contained $10 \mu \mathrm{g} \mathrm{I} / \mathrm{l}$. With the set-up the analytical sensitivity varied between 2 and $3 \mu \mathrm{g} / \mathrm{l}$. The standard was prepared from KI for analysis (Merck, Darmstadt, Germany). The I concentrations in urine from the $\mathrm{C} 1$ and $\mathrm{C} 2$ cohorts were measured in different runs. When thirty samples from the $\mathrm{C} 1$ cohort were re-measured in connection with the $\mathrm{C} 2$ urine samples, no significant differences from the first measurement results were observed.

Urinary sodium and creatinine were determined using Vitros $\mathrm{Na}+$ and creatinine slides and Vitros Chemistry Products calibrator kits on a Vitros 250 chemistry system (Ortho-Clinical Diagnostic System Inc., Rochester, NY, USA). Intra- and inter-assay CV were below $5 \%$ for both assays. Equipment was calibrated according to manufacturers' instructions and external standards included standards from the Danish Institute for External Quality Assurance for Laboratories in Health Care (DEKS). Dilution and recovery tests were satisfactory for both methods. In all assay runs, samples from the different subgroups of the population cohorts investigated were included in random order.

The $24 \mathrm{~h}$ urine samples were analysed for para-aminobenzoic acid with the use of the HPLC method described by Jakobsen et al. ${ }^{(15)}$. In short, $1 \mathrm{ml}$ urine was hydrolysed before dilution, separation, detection and quantification on reversed-phase HPLC and UV detection.

\section{Statistics}

Results are expressed as medians, with the 25 th and 75 th percentiles. Non-parametric statistics were used due to the skewed distribution of the data. The Mann-Whitney test was used to compare $\mathrm{C} 1$ and $\mathrm{C} 2$. The Wilcoxon signed ranks test was used to compare various measures of I excretion. Spearman's $\rho$ was used for correlation analyses. The Kruskal-Wallis test was used to compare medians among different intake groups of bread and fish, e.g. a multiple linear regression model (general linear model) was performed with log-transformed I excretion expressed as estimated $24 \mathrm{~h}$ urinary I excretion as the dependent variable. The following were used as independent variables: city; age and gender group; use of dietary supplements with I; milk intake; water intake; fish intake; estimated salt intake; bread intake. BMI, educational group and smoking were entered into the model one by one. $P$ values below 0.05 were considered significant. Statistical analyses were performed with the Statistical Package for Social Sciences (SPSS version 14.0; Chicago, IL, USA).

\section{Results}

Iodine intake before and after iodine fortification of bread salt and household salt

I excretion in casual urine samples in all participants, before (C1) and after (C2) I fortification expressed as a concentration and as estimated $24 \mathrm{~h}$ urinary I excretion are given in Table 1. I excretion increased significantly after fortification expressed in both ways. Furthermore, I intake determined from the FFQ without taking the fortified products into account (that means without including I added to bread and household salt) are shown in Table 1. The intake of I from non-iodized food did not change from $\mathrm{C} 1$ to $\mathrm{C} 2$ (Table 1).

The distribution of estimated $24 \mathrm{~h}$ urinary I excretion can be seen in Fig. 1. In $\mathrm{C} 220.6 \%$ had an I concentration in urine below $50 \mu \mathrm{g} / \mathrm{l}$ compared with $40.0 \%$ in $\mathrm{C} 1(P<0.001)$. Likewise, $9.3 \%$ had an estimated $24 \mathrm{~h}$ urinary I excretion below $70 \mu \mathrm{g} / \mathrm{d}$, corresponding to the lower intake level ${ }^{(18)}$, in $\mathrm{C} 2$ compared with $33.0 \%$ in $\mathrm{C} 1(P<0.001)$. For participants not taking I-containing supplements 47 and $24 \%$ in $\mathrm{C} 1$ and $\mathrm{C} 2$, respectively, had an I concentration in urine below $50 \mu \mathrm{g} / \mathrm{l}$.

To test for equality of variances in the distributions $\log$ estimated $24 \mathrm{~h}$ urinary I excretion was used to obtain a normal distribution. Log estimated $24 \mathrm{~h}$ urinary I excretions were $2.00(\operatorname{SEM} 0.32)$ and 2.18 (SEM0.28) $(P<0.001$, Levene's test).

\section{Iodine intake in various groups before and after fortification}

I intake expressed as the estimated $24 \mathrm{~h}$ urinary I excretion before and after fortification are shown in Fig. 2 for all age

Table 1. lodine excretion expressed as a concentration and as estimated $24 \mathrm{~h}$ urinary iodine excretion and iodine intake from non-fortified food before (C1) and after (C2) fortification

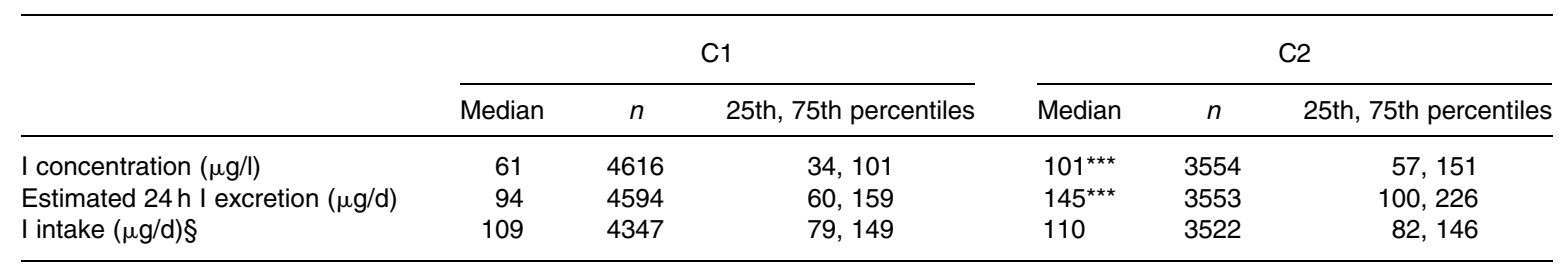

Median values were significantly different from those of $C 1$ (Mann-Whitney test): ${ }^{\star \star \star} P<0.001$.

$\S$ Calculated without including I in fortified salt. 


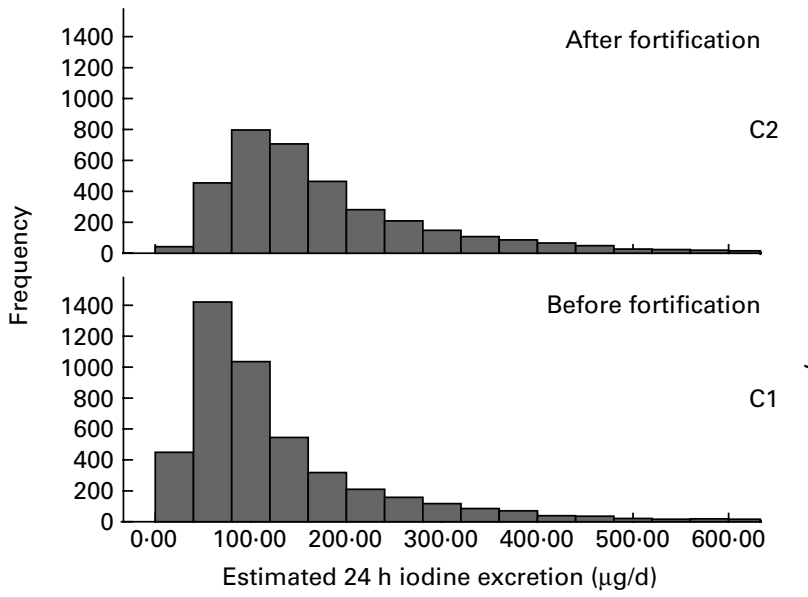

Fig. 1. Intake distribution of iodine, expressed as estimated $24 \mathrm{~h}$ urinary iodine excretion $(\mu \mathrm{g} / \mathrm{d})$, before (cross-sectional study $\mathrm{C} 1$ ) and after (C2) iodine fortification.

groups in both cities. I intake increased significantly in all groups. The I excretion indicated an intake below the recommended level $(150 \mu \mathrm{g} / \mathrm{d})$ in all groups before I fortification. After the fortification I intake was still below the recommended level in the two youngest age groups in both cities and in women 40-45 years of age in Aalborg.

The I excretion expressed as a concentration did also increase significantly in all groups (data not shown; $P<0.001$ ).

The 95th percentile was below the safe upper level of $600 \mu \mathrm{g} / \mathrm{d}$ in all groups ${ }^{(18,19)}$, even if only participants taking dietary supplements with I were included (data not shown). Furthermore, the median urinary I concentration was below

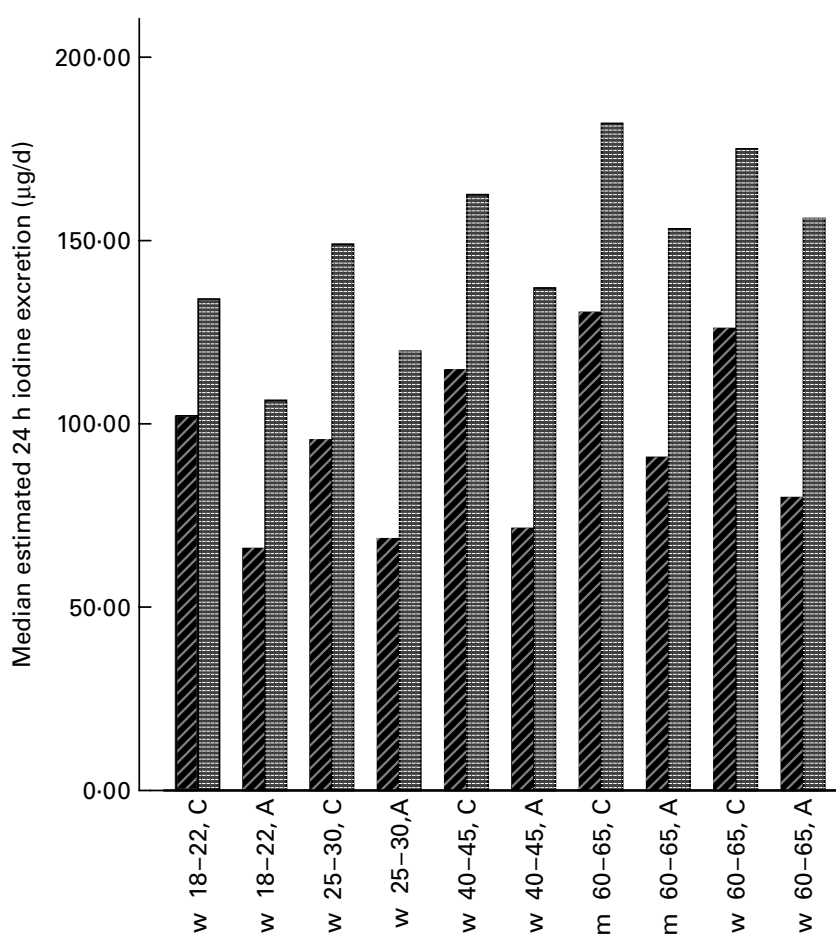

Fig. 2. Median estimated $24 \mathrm{~h}$ urinary I excretion $(\mu \mathrm{g} / \mathrm{d})$ in all age and sex groups before ( $\mathbf{z}, \mathbf{C} 1)$ and after ( $\mathbf{\square}, \mathrm{C} 2)$ iodine fortification. lodine excretion increased significantly in all age and sex groups $(P<0.001)$. A, Aalborg; C, Copenhagen; m, men; w, women.
$200 \mu \mathrm{g} / \mathrm{d}$ in all groups if only participants taking dietary supplements with I were included.

\section{Iodine intake in participants not taking dietary supplements} with iodine

Dietary supplements containing I were taken by $34 \%$ in $\mathrm{C} 1$ and $29 \%$ in $\mathrm{C} 2 \quad(P<0.001$ for difference between $\mathrm{C} 1$ and $\mathrm{C} 2$ ), the use of dietary supplements was highest in elderly women $(38 \%)$. I excretion in participants not taking dietary supplements with $\mathrm{I}$ is shown in Table 2 and in subjects taking I-containing supplements in Table 3. I excretion was significantly lower in participants who did not take dietary supplements with I than in participants who took I supplements $(P<0 \cdot 001)$.

\section{Iodine excretion in $24 \mathrm{~h}$ urine samples}

In both $\mathrm{C} 1$ and $\mathrm{C} 2$ a subsample of participants in the age groups 25-30 years and 60-65 years collected $24 \mathrm{~h}$ urine samples. I excretion in $24 \mathrm{~h}$ urine in these subgroups is shown in Table 4. Furthermore, estimated $24 \mathrm{~h}$ urinary I excretion in the same subjects is included for comparison. More participants took dietary supplements containing I in the subgroups than in the entire cohort. In C1 54, 44, 59 and $42 \%$ of the participants, respectively, in the four groups took a supplement. In $\mathrm{C} 2$ the frequencies were: $33,25,53$ and $33 \%$, respectively. The $24 \mathrm{~h}$ urinary I excretion for all in the subgroup in $\mathrm{C} 2$ who did not take dietary supplements containing I was 156 (range 127-211) $\mu \mathrm{g} / 24 \mathrm{~h}$.

\section{Intake of fortified food and increase in iodine intake at group level}

The median I intake from bread was calculated to $20 \cdot 3$ (range $11.6-29.5) \mu \mathrm{g} / \mathrm{d}$ and was lowest in the youngest age groups. The correlation between mean increase in I intake and bread intake in the ten age and sex groups was $\rho 0 \cdot 70, P=0.03$. Likewise, the correlation between increase in I intake and estimated salt intake in the ten groups was $\rho 0.74, P=0.02$.

\section{Determinants of iodine intake after fortification}

Estimated $24 \mathrm{~h}$ urinary I excretion with different intakes of I-rich food are given in Table 5. The dietary factors that might be related to I intake were also explored in a general linear model (Table 5). Inclusion of BMI, smoking (yes, no) and education into the model changed the association only marginally. A low BMI was associated with a low I intake $(P<0.001)$ whereas smoking and education were not significantly associated with I intake.

Lastly, participants who stated to be allergic to I ( $n$ 31) had an estimated $24 \mathrm{~h}$ urinary I excretion of 132 (range 101-222) $\mu \mathrm{g} / \mathrm{d}$ compared to 146 (range 99-226) $\mu \mathrm{g} / \mathrm{d}$ in the other participants $(P=0.6)$. Likewise, the estimated $24 \mathrm{~h}$ urinary I excretion did not differ between vegetarians (143 (range 97-209) $\mu \mathrm{g} / \mathrm{d} ; n$ 52) and non-vegetarians (146 (range $100-226) \mu \mathrm{g} / \mathrm{d} ; n$ 3488) $(P=0 \cdot 6)$.

\section{Discussion}

The I intake increased significantly in all investigated age groups after fortification of household salt and bread salt 
Table 2. Estimated $24 \mathrm{~h}$ urinary iodine excretion in urine in participants not taking dietary supplements with iodine before (C1) and after (C2) fortification

\begin{tabular}{lccccccc}
\hline & \multicolumn{3}{c}{ C1 } & & \multicolumn{3}{c}{ C2 } \\
\cline { 2 - 3 } \cline { 6 - 8 } & Median $(\mu \mathrm{g} / \mathrm{d})$ & $n$ & 25th, 75th percentiles & & Median $(\mu \mathrm{g} / \mathrm{d})$ & $n$ & 25th, 75th percentiles \\
\hline All, Copenhagen & 94 & 1569 & 66,136 & & $140^{\star \star \star}$ & 1261 & 100,200 \\
All, Aalborg & 63 & 1442 & 43,92 & & $120^{\star \star \star}$ & 1255 & 84,162 \\
All & 78 & 3011 & 52,116 & & $128^{\star \star \star}$ & 2516 & 92,183 \\
\hline
\end{tabular}

Median values were significantly different from those of $C 1$ (Mann-Whitney test): ${ }^{\star \star \star} P<0.001$.

with 13 parts per million I. The fortification programme has moved the distribution of the I intake among the participants to the right, which means that not only has the median intake increased, but in addition fewer individuals had a low I intake after fortification (C2) than before fortification (C1). The lowest I intake was found in the youngest age groups in both cities and in 40-45-year-old women living in Aalborg. Dietary determinants of I intake in $\mathrm{C} 2$ were milk, water and salt intake whereas bread and fish intake were not related with I intake when included in a model together with other variables which influence I excretion.

No change in the intake of I-rich food could be observed between $\mathrm{C} 1$ and $\mathrm{C} 2$, indicating that the increased I intake was not caused by changes in dietary habits. Furthermore, slightly fewer individuals took I-containing dietary supplements in $\mathrm{C} 2$ than in $\mathrm{C} 1$, thus the increase in I excretion is most likely to be caused by the I fortification.

After the fortification the median urinary I concentration in the investigated population was $101 \mu \mathrm{g} / \mathrm{l}$ indicating sufficient I intake according to $\mathrm{WHO}^{(20)}$. When expressed as the estimated $24 \mathrm{~h}$ urinary I excretion, which can be compared with the recommended intake of $150 \mu \mathrm{g} / \mathrm{d}^{(18,20,21)}$, the intake was close to the recommended for the group as a whole. The frequency of urinary I concentrations $<50 \mu \mathrm{g} / \mathrm{l}(20.6 \%)$ was quite high for a population with a median I concentration $>100 \mu \mathrm{g} / \mathrm{l}^{(22)}$. This underscores the importance of identifying subgroups with the lowest I intake. However, the estimated $24 \mathrm{~h}$ urinary I excretion was below the lower level of intake, $70 \mu \mathrm{g} / \mathrm{d}^{(18,19)}$, in only $9 \%$ of the samples. The lower intake level refers to the level below which an intake could lead to deficiency symptoms in some individuals ${ }^{(18)}$. In the part of the population which does not take dietary I supplements, the median I excretion was below the recommended level, especially for individuals living in Aalborg. The risk of excessive I intake is very low in this adult population. The 95th percentile for I intake was below the safe upper level of $600 \mu \mathrm{g} / \mathrm{d}$ in all investigated groups. Likewise, median urinary I concentration was below $300 \mu \mathrm{g} / \mathrm{d}$ in all investigated groups, which means that no groups can be regarded as 'excessive' according to WHO definitions ${ }^{(21)}$.

The mean increase in I intake was about $50 \mu \mathrm{g} / \mathrm{d}$ which is identical to the targeted increase in I intake with a fortification level of 13 parts per million ${ }^{(23)}$. However, the increase in I intake does not seem to be equally distributed among age groups. The youngest age groups had the lowest increase in intake which is associated with a lower intake of bread and salt in these age groups compared with the elderly age groups. The increase in I intake in the various groups from $\mathrm{C} 1$ to $\mathrm{C} 2$ correlated with the intake of bread and salt. A more thorough investigation regarding factors affecting the increase in I intake after fortification is not possible from the present study, but can be performed in a possible follow-up study of $\mathrm{C} 1$.

Time of day may affect I excretion in the urine ${ }^{(24)}$. In both studies samples were non-fasting collected mainly between 08.00 and 16.00 hours and less than $7 \%$ sampled after 16.00 hours. Thus, the results are comparable. However, according to Als et al. ${ }^{(24)}$ the time of sampling in the two studies probably underestimates the real I intake a little as I excretion increases during the day.

In the present study risk groups for low I intake with regard to age and sex were women below 30 years of age and women aged 40-45 years living in Aalborg. Furthermore, subjects not taking dietary supplements with I were at risk of low I intake. Few studies have dealt with I excretion in various age groups. Als et al. ${ }^{(25)}$ did not find a lower I excretion, expressed as a concentration, in women 21-35 years of age than in women 51-65 years of age. When expressed as a concentration the I excretion was not lower in the youngest age groups compared to the other age groups in the present study either.

We chose to express the I excretion as the estimated $24 \mathrm{~h}$ urinary I excretion because this expression takes advantage of the dilution of the urine, and a satisfactory agreement between estimated $24 \mathrm{~h}$ urinary I excretion and measured $24 \mathrm{~h}$ urinary I excretion has been found ${ }^{(13,14)}$. When using the concentration, the I excretion was highest in the two youngest age groups and lowest in women more than 40 years of age (data not shown).

Table 3. Estimated $24 \mathrm{~h}$ urinary iodine excretion in urine in participants taking dietary supplements with iodine before (C1) and after (C2) fortification

\begin{tabular}{|c|c|c|c|c|c|c|}
\hline & \multicolumn{3}{|c|}{$\mathrm{C} 1$} & \multicolumn{3}{|c|}{$\mathrm{C} 2$} \\
\hline & Median $(\mu \mathrm{g} / \mathrm{d})$ & $n$ & 25th, 75 th percentiles & Median $(\mu \mathrm{g} / \mathrm{d})$ & $n$ & 25th, 75 th percentiles \\
\hline All, Aalborg & 130 & 733 & 73,238 & $209^{* * *}$ & 519 & 138,320 \\
\hline All & 157 & 1583 & 92,267 & $222^{\star \star \star}$ & 1037 & 145,346 \\
\hline
\end{tabular}

Median values were significantly different from those of $C 1$ (Mann-Whitney test): ${ }^{\star \star \star} P<0.001$. 
Table 4. lodine excretion in $24 \mathrm{~h}$ urine in subgroups who collected $24 \mathrm{~h}$ urine samples and estimated $24 \mathrm{~h}$ urinary iodine excretion for the same subjects as comparison, before (C1) and after (C2) fortification

\begin{tabular}{|c|c|c|c|c|}
\hline & \multicolumn{2}{|r|}{ C1 } & \multicolumn{2}{|c|}{$\mathrm{C} 2$} \\
\hline & Median & 25th, 75th percentiles & Median & , 75th percentiles \\
\hline I excretion in $24 \mathrm{~h}$ urine $(\mu \mathrm{g} / \mathrm{d})$ & 140 & 110,221 & $201^{*}$ & 152,280 \\
\hline Estimated $24 \mathrm{~h}$ I excretion ( $\mu \mathrm{g} / \mathrm{d})$ & 116 & 100,204 & 134 & 86,261 \\
\hline Women $25-30$ years, Aalborg & & $n 45$ & & \\
\hline I excretion in $24 \mathrm{~h}$ urine $(\mu \mathrm{g} / \mathrm{d})$ & 96 & 72,180 & $171^{\star \star}$ & 126,219 \\
\hline Estimated $24 \mathrm{~h}$ I excretion $(\mu \mathrm{g} / \mathrm{d})$ & $64 \dagger$ & 38,90 & 122 & 96,173 \\
\hline Women 60-65 years, Copenhagen & & $n 22$ & & \\
\hline I excretion in $24 \mathrm{~h}$ urine $(\mu \mathrm{g} / \mathrm{d})$ & 180 & 108,237 & $201^{*}$ & 151,286 \\
\hline Estimated $24 \mathrm{~h}$ I excretion ( $\mu \mathrm{g} / \mathrm{d})$ & 135 & 88,307 & $223 \ddagger$ & 164,373 \\
\hline Women $60-65$ years, Aalborg & & $n 36$ & & \\
\hline I excretion in $24 \mathrm{~h}$ urine $(\mu \mathrm{g} / \mathrm{d})$ & 99 & 80,162 & $158^{\star \star \star}$ & 117,230 \\
\hline Estimated $24 \mathrm{~h}$ I excretion $(\mu \mathrm{g} / \mathrm{d})$ & 81 & 44,164 & 169 & 111,263 \\
\hline
\end{tabular}

Median values were significantly different from those of $\mathrm{C} 1$ (Mann-Whitney test): ${ }^{*} P=0.05,{ }^{* *} P=0.002,{ }^{* \star *} P=0.001$.

Median value was significantly different from that of the measured I excretion (Wilcoxon signed ranks test): $† P<0.001$.

Median value was significantly different from that of the Aalborg subgroup in the same age group: $\ddagger P<0.01$.

This differs from the results when expressed as estimated $24 \mathrm{~h}$ urinary I excretion. Thus, when investigating a population with a different intake of liquids between groups or when comparing various populations, the conclusion may depend on the expression being used.

There are uncertainties with the estimated $24 \mathrm{~h}$ urinary I excretion as with the urinary concentration. Especially the use of a table value for daily creatinine excretion introduces a possible error. If the creatinine values used are a little too high then the estimated $24 \mathrm{~h}$ urinary I excretion is overestimated. The results shown in Table 4 indicate an underestimation more than an overestimation of the I excretion when expressed as estimated $24 \mathrm{~h}$ urinary I excretion in some groups, however, it was only significantly lower from measured $24 \mathrm{~h}$ urinary I excretion in one group.

The $24 \mathrm{~h}$ urinary I excretion is said to be the gold standard, but due to practical reasons this was only measured in a subgroup. Results of the $24 \mathrm{~h}$ urinary samples showed an intake

Table 5. Dietary determinants of iodine intake in cross-sectional study C2 (after fortification)

\begin{tabular}{|c|c|c|c|c|c|}
\hline & \multicolumn{3}{|c|}{ Estimated $24 \mathrm{~h}$ I excretion $(\mu \mathrm{g} / \mathrm{d})$} & \multirow[b]{2}{*}{ Kruskal-Wallis test } & \multirow[b]{2}{*}{ General linear model§ } \\
\hline & Median & $n$ & 25th, 75th percentiles & & \\
\hline \multicolumn{6}{|c|}{ Bread intake $(\mathrm{g} / \mathrm{d})$} \\
\hline$<50$ & 140 & 781 & 91,213 & $P<0.001$ & $P=0.36$ \\
\hline $50-150$ & 143 & 2085 & 99,223 & & \\
\hline$>150$ & 156 & 704 & 106,252 & & \\
\hline \multicolumn{6}{|l|}{ Fish intake } \\
\hline Quartile 1 & 138 & 878 & 93,209 & $P<0.001$ & $P=0.42$ \\
\hline Quartile 2 & 139 & 877 & 97,221 & & \\
\hline Quartile 3 & 145 & 878 & 100,223 & & \\
\hline Quartile 4 & 162 & 877 & 112,245 & & \\
\hline \multicolumn{6}{|l|}{ Water intake } \\
\hline Quartile 1 & 134 & 876 & 92,205 & $P<0.001$ & $P=0.02$ \\
\hline Quartile 2 & 138 & 876 & 97,217 & & \\
\hline Quartile 3 & 156 & 875 & 105,246 & & \\
\hline Quartile 4 & 155 & 876 & 112,245 & & \\
\hline \multicolumn{6}{|c|}{ I-containing supplements } \\
\hline No & 128 & 2516 & 92,183 & $P<0.001$ & $P<0.001$ \\
\hline Yes & 222 & 1037 & 145,346 & & \\
\hline \multicolumn{6}{|c|}{ Milk intake (glasses/d) } \\
\hline$<0.2$ & 129 & 466 & 87,208 & $P<0.001$ & $P<0.001$ \\
\hline $0 \cdot 2-1$ & 132 & 873 & 93,205 & & \\
\hline $1 \cdot 01-2$ & 146 & 1085 & 100,228 & & \\
\hline $2 \cdot 01-3$ & 164 & 530 & 113,253 & & \\
\hline$>3$ & 163 & 555 & 111,249 & & \\
\hline \multicolumn{6}{|c|}{ Estimated salt intake } \\
\hline Quartile 1 & 113 & 885 & 80,177 & $P<0.001$ & $P<0.001$ \\
\hline Quartile 2 & 129 & 886 & 93,197 & & \\
\hline Quartile 3 & 161 & 886 & 114,244 & & \\
\hline Quartile 4 & 187 & 885 & 130,294 & & \\
\hline
\end{tabular}

$\S$ Dependent variable: log estimated $24 \mathrm{~h}$ urinary I excretion. Independent variables: age, sex, city and all variables in the table. 
above the recommended for both age groups investigated in both cities after fortification. Even the median value for all in the subgroup who did not take dietary supplements with I was higher than the recommended intake. Results in the subgroup differ from results of the whole study population as I excretion was not lower in the 25-30 year age group than in the 60-65 year age group. The estimated $24 \mathrm{~h}$ urinary I excretion was significantly higher in 60-65-year-old women living in Copenhagen who participated in the subgroup (which can be explained by a more frequent use of dietary supplements with I) compared with all included 60-65-year-old women, but did not differ in the other groups between the subgroup and the whole cohort. So, the reason for the discrepancy in the results is most likely the uncertainties with the expression used for urinary I excretion in the whole study population.

An effect on I excretion is not sufficient to evaluate the efficacy of an I fortification programme. An effect on thyroid size or goitre incidence should also be discovered, but the time before the full effect on the thyroid can be observed seems to vary from study to study. A notable observation is that the time taken for an effect to show increases with age ${ }^{(3)}$. In DanThyr, however, we found a significant decrease in thyroid size in all groups except the youngest women living in Copenhagen ${ }^{(10)}$. In this age group the decrease was only borderline significant, however, the group had the smallest thyroid glands before fortification. Additionally, in both cities the thyroid volume is now within the normal range in the youngest age groups ${ }^{(10)}$. Since thyroid size increases with age in a mild I-deficient population like the Danish, a sufficient I intake as well as a normal thyroid size is needed to conclude whether the I intake is sufficient. Before considering an increase in the I content in salt, results from a follow-up study of subjects participating in the first study and results from a register study to follow the development in hyper- and hypothyroidism should be evaluated.

Milk was found to be the strongest dietary determinant of I intake after fortification as it was before fortification ${ }^{(5)}$. Bread intake was not significantly associated with the estimated $24 \mathrm{~h}$ urinary I excretion when included in a multiple linear model, nor if salt intake was not included in the model (data without salt intake not shown). Surprisingly, salt intake was found to have a strong positive association with estimated $24 \mathrm{~h}$ urinary I excretion, although only household salt and salt used in bread production are iodized (natural I content in salt is low). Household salt makes up no more than approximately $10 \%$ of the total salt intake in Denmark (Andersen, personal communication). Remer et al. ${ }^{(26)}$ likewise found that milk and sodium excretion were the dietary factors most strongly related to I excretion in Germany, although mostly household salt and only to a smaller degree salt used by the food industry is iodized in Germany.

Risk groups with regard to dietary intake are first of all groups with a low milk intake and secondly groups with low intake of salt from bread and household salt. Low BMI was associated with a low intake of I probably because of a low intake of food in general. Smoking and education were not found to be associated with I intake.

According to Delange ${ }^{(1)}$, I deficiency is eliminated in fourteen out of thirty-one countries in Western and Central Europe. However, even if the population median I excretion indicates a sufficient I intake, some population groups could still have an insufficient intake and it is important to identify these subgroups. Furthermore, in some countries an increase in I deficiency has been seen ${ }^{(27,28)}$. Continued monitoring in various population groups is important to achieve and maintain an optimal I intake. Dietary habits can change, for instance a lower intake of milk, salt or bread would lead to a lower I intake. I content in imported salt and bread is not regulated, so a higher market share of imported salt and imported bread can both lead to a lower or a higher I intake depending on the I content in the imported food.

\section{Conclusion}

After mandatory I fortification was introduced in Denmark the I intake has increased markedly in all investigated groups. The mean increase in I intake was close to the planned $50 \mu \mathrm{g} / \mathrm{d}$. However, there are still groups with an intake below the recommended level whereas we identified no groups with excessive I intake. With regard to sex and geography the groups with risk of low intake are still women living in Aalborg and other places in Denmark with a low I content in drinking water. Furthermore, subjects with a low milk and salt intake are at risk of low I intake. Additionally, subjects with low BMI had a lower I intake than subjects with a high BMI. Risk groups with regard to lifestyle factors could not be identified.

\section{Acknowledgements}

The study was supported by grants from Tømmerhandler Vilhelm Bang Foundation, the Copenhagen Hospital Cooperation Research Foundation, the 1991 Pharmacy Foundation, the Danish Medical Foundation, The Health Insurance Foundation, North Jutland County Research Foundation and Musikforlæggerne Agnes og Knut Mørks Foundation. A. C., P. V., I. B. P., N. K. and L. B. R. collected the data. L. O., T. J., P. L. and H. P. contributed to the design of DanThyr. All took part in critical revision of the manuscript and in final approval of the manuscript. There are no conflicts of interest.

\section{References}

1. Delange FM (2003) Control of iodine deficiency in Western and Central Europe. Cent Eur J Public Health 11, 120-123.

2. Bürgi H (1993) Iodization of salt and food. Technical and legal aspects. In Iodine Deficiency in Europe. A Continuing Concern, pp. 261-268 [F Delange, JT Dunn and D Glinoer, editors]. New York and London: Plenum Press.

3. Zimmermann MB (2004) Assessing iodine status and monitoring progress of iodized salt programs. J Nutr 134, 1673-1677.

4. Als C, Haldimann M, Minder C \& Gerber H (2004) Pilot study of urinary iodine concentration and of biochemical thyroid parameters before and after cautious public health intervention on salt iodide content: the Swiss longitudinal 1996-2000 iodine study. Eur J Clin Nutr 58, 1201-1210.

5. Rasmussen LB, Ovesen L, Bülow I, Jørgensen T, Knudsen N, Laurberg P \& Perrild H (2002) Dietary iodine intake and urinary iodine excretion in a Danish population: effect of geography, supplements and food choice. Br J Nutr 87, 61-69. 
6. Knudsen N, Bülow I, Jørgensen T, Laurberg P, Ovesen L \& Perrild H (2000) Goitre prevalence and thyroid abnormalities at ultrasonography: a comparative epidemiological study in two regions with slightly different iodine status. Clin Endocrinol 53, 479-485.

7. Rasmussen LB, Larsen EH \& Ovesen L (2000) Iodine content in drinking water and other beverages in Denmark. Eur J Clin Nutr 54, 57-60.

8. Pedersen KM, Laurberg P, Nøhr S, Jørgensen A \& Andersen S (1999) Iodine in drinking water varies by more than 100 -fold in Denmark. Importance for iodine content of infant formulas. Eur J Endocrinol 140, 400-403.

9. Laurberg P, Jorgensen T, Perrild H, Ovesen L, Knudsen N, Pedersen IB, Rasmussen LB, Carle A \& Vejbjerg P (2006) The Danish investigation on iodine intake and thyroid disease, DanThyr: status and perspectives. Eur J Endocrinol 155, 219-228.

10. Vejbjerg P, Knudsen N, Perrild H, Carle A, Laurberg P, Pedersen IB, Rasmussen LB, Ovesen L \& Jorgensen T (2007) Effect of a mandatory iodization program on thyroid gland volume based on individuals' age, gender, and preceding severity of dietary iodine deficiency: a prospective, population-based study. J Clin Endocrinol Metab 92, 1397-1401.

11. Rasmussen LB, Ovesen L, Bülow I, Jørgensen T, Knudsen N, Laurberg P \& Perrild H (2001) Evaluation of a semi-quantitative food frequency questionnaire to estimate iodine intake. Eur J Clin Nutr 55, 287-292.

12. Kesteloot H \& Joossens JV (1997) On the determinants of the creatinine clearance: a population study. J Hum Hyperten 10, 245-249.

13. Rasmussen LB, Ovesen L \& Christiansen E (1999) Day-to-day and within-day variation in urinary iodine excretion. Eur J Clin Nutr 53, 401-407.

14. Knudsen N, Christiansen E, Brandt-Christensen M, Nygaard B \& Perrild H (2000) Age- and sex-adjusted iodine/creatinine ratio. A new standard in epidemiological surveys? Evaluation of three different estimates of iodine excretion based on casual urine samples and comparison to $24 \mathrm{~h}$ values. Eur $J$ Clin Nutr 54, 361-363.

15. Jakobsen J, Ovesen L, Fagt S \& Pedersen AN (1997) Para-aminobenzoic acid used as a marker for completeness of 24 hour urine: assessment of control limits for a specific HPLC method. Eur J Clin Nutr 51, 514-519.

16. Wilson B \& van Zyl A (1967) The estimation of iodine in thyroidal amino acids by alkaline ashing. $S$ Afr J Med Sci 32, $70-82$.
17. Laurberg P (1987) Thyroxine and 3,5,3'-triiodothyronine content of thyroglobulin in thyroid needle aspirates in hyperthyroidism and hypothyroidism. $J$ Clin Endocrinol Metab 119, $125-131$.

18. Nordic Council of Ministers (2004) Nordic Nutrition Recommendations 2004. Nord 2004:13. Copenhagen: Nordic Council of Ministers.

19. Scientific Committee on Food (2002) Opinion of the Scientific Committee on Food on the tolerable upper intake level of iodine http://ec.europa.eu/food/fs/sc/scf/out146_en.pdf

20. World Health Organization (2007) World Health Organization Micronutrient Deficiency Information System. Geneva: WHO.

21. World Health Organization/United Nations Children's Fund/ International Council for the Control of Iodine Deficiency Disorders (2001) Assessment of Iodine Deficiency Disorders and Monitoring their Elimination. A Guide for Programme Managers. Geneva: WHO.

22. Delange F, de BB \& Burgi H (2002) Determining median urinary iodine concentration that indicates adequate iodine intake at population level. Bull World Health Organ 80, 633-636.

23. Rasmussen LB, Ovesen L, Christensen T, Knuthsen P, Larsen EH, Lyhne N, Okholm B \& Saxholt E (2007) Iodine content in bread and salt in Denmark after iodization and the influence on iodine intake Int J Food Sci Nutr 58, 231-239.

24. Als C, Helbling A, Peter K, Haldimann M, Zimmerli B \& Gerber H (2000) Urinary iodine concentration follows a circadian rhythm: a study with 3023 spot urine samples in adults and children. J Clin Endocrinol Metab 85, 1367-1369.

25. Als C, Keller A, Minder C, Haldimann M \& Gerber H (2000) Age- and gender-dependent urinary iodine concentrations in an area-covering population sample from the Bernese region in Switzerland. Eur J Endocrinol 143, 629-637.

26. Remer T, Fonteyn N, Alexy U \& Berkemeyer S (2006) Longitudinal examination of 24-h urinary iodine excretion in schoolchildren as a sensitive, hydration status-independent research tool for studying iodine status. Am J Clin Nutr 83, 639-646.

27. Guttikonda K, Burgess JR, Hynes K, Boyages S, Byth K \& Parameswaran V (2002) Recurrent iodine deficiency in Tasmania, Australia: a salutary lesson in sustainable iodine prophylaxis and its monitoring. J Clin Endocrinol Metab 87, $2809-2815$.

28. Skeaff SA, Thomson CD \& Gibson RS (2003) Iodine Deficiency Disorders (IDD) in the New Zealand population: another example of an outmoded IDD control programme. Asia Pac J Clin Nutr 12, Suppl., S15-S16. 